\title{
Triiodothyronine Potentiates Vasorelaxation via PKG/VASP Signaling in Vascular Smooth Muscle Cells
}

\author{
Sherin Samuel ${ }^{a} \quad$ Kuo Zhang ${ }^{b}$ Yi-Da Tang ${ }^{b}$ A. Martin Gerdes \\ Maria Alicia Carrillo-Sepulvedac \\ aDepartment of Life Sciences, New York Institute of Technology, Old Westbury, New York, USA; \\ bDepartment of Internal Medicine, State Key Laboratory of Cardiovascular Disease, Fuwai Hospital, \\ National Center for Cardiovascular Diseases, Chinese Academy of Medical Sciences and Peking Union \\ Medical College, Beijing, China; 'Department of Biomedical Sciences, New York Institute of Technology \\ - College of Osteopathic Medicine, Old Westbury, New York, USA
}

\section{Key Words}

Triiodothyronine (T3) - PKG • p-VASP • Vascular smooth muscle cell • Vasorelaxation • Endothelial cell $\bullet$ Non-genomic effect

\begin{abstract}
Background/Aims: Vascular relaxation caused by Triiodothyronine (T3) involves direct activation of endothelial cells (EC) and vascular smooth muscle cells (VSMC). Activation of protein kinase $G$ (PKG) has risen as a novel contributor to the vasorelaxation mechanism triggered by numerous stimuli. We hypothesize that T3-induced vasorelaxation involves PKG/vasodilator-stimulated phosphoprotein (VASP) signaling pathway in VSMC. Methods: Human aortic endothelial cells (HAEC) and VSMC were treated with T3 for short (2 to 60 minutes) and long term (24 hours). Nitric oxide (NO) production was measured using DAFFM. Expression of protein targets was determined using western blot. For functional studies, rat aortas were isolated and treated with T3 for 20 minutes and mounted in a wire myograph. Relaxation was measured by a concentration-dependent response to acetylcholine (ACh) and sodium nitroprusside (SNP). Results: Aortas stimulated with T3 exhibited augmented sensitivity to ACh and SNP-induced relaxation, endothelium-dependent and endotheliumindependent responses, respectively. T3 directly increased vasorelaxation, which was abolished in the presence of a PKG inhibitor. T3 markedly induced phosphorylation of Akt, eNOS and consequently increased NO production in EC. Likewise, T3 induced phosphorylation of VASP at serine 239 via the PKG pathway in VSMC. Conclusion: Our findings have uncovered a PKG/VASP signaling pathway in VSMC as a key molecular mechanism underlying T3-induced vascular relaxation.
\end{abstract}




\section{Cellular Physiology Cell Physiol Biochem 2017;41:1894-1904 \begin{tabular}{l|l} 
and Biochemistry Published onIne: April 04, 2017 & $\begin{array}{l}\text { C } 2017 \text { The Author(s). Published by S. Karger AG, Basel } \\
\text { www.karger.com/cpb }\end{array}$
\end{tabular} \\ Samuel et al.: Vasodilatory Effect of T3 and PKG/VASP Signaling Pathway}

\section{Introduction}

Thyroid hormones (THs) play a crucial role in the maintenance of cardiovascular homeostasis under pathophysiological conditions, especially in the regulation of vascular tone [1-3]. T3 is considered the biologically active form of TH. It is mainly generated from 5 '-monodeiodination of thyroxine (T4) through type I and type II iodothyronine deiodinase in peripheral tissues. [4]. Importantly, THs receptors and deiodinases are expressed in EC from microvasculature [5]. Whereas T3 is essential to maintain vascular function, subtle deficit of T3 leads to a series of disorders in the vascular system. Hypothyroidism, characterized by low levels of T3, has been associated with cardiovascular diseases such as hypertension and diabetes [6-8]. Deficiency of T3 is correlated with endothelial dysfunction, a common factor in most vascular diseases. Several animals and human studies have indicated that therapeutic use of low doses of THs promotes protective effects on the cardiovascular system, including improvement of heart function and vascular regulation [9].

It is well known that T3 induces rapid vascular relaxation via both endotheliumdependent and endothelium-independent mechanisms [10-12]. Indeed, evidence has increasingly demonstrated that, besides EC, VSMC are an important target of T3 effects, which directly contribute to T3-induced vascular relaxation [13]. However, the integrative mechanisms displayed by T3 on these two cellular types are still lacking.

The classical mechanism by which T3 exerts its effects occurs via genomic signaling. T3 binds to its nuclear receptors coupled to T3 response elements (TRE) in the promoter regions of target genes to regulate transcription [14]. A new line of investigation has demonstrated that $\mathrm{T} 3$ has a rapid effect, including rapid vasodilation. It has been proposed that acute effects of T3 are mediated by non-genomic mechanisms involving activation of sodium, potassium, and calcium membrane ion channels and several signaling pathways in cardiomyocytes and vascular cells $[1,15]$. T3 also activates many downstream signal-transducing pathways via its binding to integrin $\alpha v \beta 3$, located within the plasma membrane [16-19]. Hiroi et al. demonstrated that activation of endothelial nitric oxide synthase (eNOS) through the phosphatidylinositol-3-kinase/protein kinase-B (PI3K/Akt) pathway mediates T3-induced rapid vascular relaxation [20]. We previously demonstrated that T3-induced vasorelaxation partially occurs via a non-genomic pathway and involves PI3K/Akt/NO signaling in VSMC [13]. However, the comprehensive mechanisms underlying the non-genomic effects of T3 in VSMC need further exploration.

NO released by EC diffuses into VSMC activating soluble guanylate cyclase, subsequently leading to the activation of the cyclic guanosine monophosphate (cGMP)-dependent protein kinase (PKG) signaling pathway $[18,19]$. Once activated, PKG causes vascular relaxation via phosphorylation of vasodilator-stimulated phosphoprotein (VASP) in VSMC [16, 21-23].

Given that the cGMP-dependentPKG pathway has recently been identified as a mechanism involved in vascular relaxation and TH causes vascular relaxation through VSMC, we sought to determine whether T3 causes vasorelaxation via PKG-VASP signaling. Moreover, results from this study will provide important clinical implications of T3 as a potential vasodilator agent to treat vascular conditions that exhibit impairment of vasodilation.

\section{Material and Methods}

\section{Animals and Experimental Procedures}

Thoracic aortas from twelve-week-old male Sprague Dawley rats (350-400 g) were utilized in ex vivo experiments using a wire myograph. Prior to isolation of aortas, all rats were maintained on a 12 hours light-dark cycle and had ad libitum access to standard rodent chow and drinking water. All procedures were conducted in accordance with the National Institutes of Health (NIH, Publication N.85-23, revised 1996) Guidelines for the Care and Use of Laboratory Animals. All of the experiments were approved by the Institutional Animal Care and Use Committee at College of Osteopathic Medicine of New York Institute of Technology. 


\section{Cellular Physiology Cell Physiol Biochem 2017;41:1894-1904 \begin{tabular}{l|l} 
and Biochemistry Published onIIne: April04, 2017 & $\begin{array}{l}\text { D } 2017 \text { The Author(s). Published by S. Karger AG, Basel } \\
\text { www.karger.com/cpb }\end{array}$
\end{tabular} \\ Samuel et al.: Vasodilatory Effect of T3 and PKG/VASP Signaling Pathway}

Vascular Reactivity

Rats were euthanasized with isoflurane (via nasal 5\% in $100 \% \mathrm{O}_{2}$ ), thoracic aortas were removed, carefully cleaned of perivascular fat in oxygenated Krebs buffer $(130 \mathrm{mM} \mathrm{NaCl}, 14.9 \mathrm{mM} \mathrm{NaHCO}, 4.7 \mathrm{mM}$ $\mathrm{KCl}, 1.18 \mathrm{mM} \mathrm{KH}_{2} \mathrm{PO}_{4}, 1.17 \mathrm{mM} \mathrm{MgSO}_{4}-7 \mathrm{H}_{2} \mathrm{O}, 1.56 \mathrm{mM} \mathrm{CaCl}_{2}-2 \mathrm{H}_{2} \mathrm{O}, 0.026 \mathrm{mM}$ EDTA, $5.5 \mathrm{mM}$ glucose, $\mathrm{pH}$ 7.4), and cut into rings ( $2 \mathrm{~mm}$ in length). Aortic rings were mounted in an isometric myograph (Model 620M-DMT, Copehangen, Denmark). Changes in force were recorded using a PowerLab 8/35 data acquisition system (ADInstruments Pty Ltd., Castle Hill, Australia), equilibrated with Krebs buffer for 30 minutes, and gassed with $5 \% \mathrm{CO}_{2}$ in $95 \% \mathrm{O}_{2}$ at $37^{\circ} \mathrm{C}$, as described previously [13]. In all experiments, aortic ring integrity was assessed by stimulation with $120 \mathrm{mM} \mathrm{KCl}$. To test for the presence of endothelium, segments were contracted with $1 \mu \mathrm{M}$ PE from Sigma-Fluka (St. Louis, MO, US) and once the vessels reached a stable maximum tension, the vessels were stimulated with $10 \mu \mathrm{M}$ ACh from Sigma Aldrich (St.Louis, MO, US) and relaxation was confirmed (greater than 80\%) [24]. Cumulative concentration-response curves to ACh (1 nM - $10 \mu \mathrm{M})$ and SNP $(1 \mathrm{nM}-10 \mu \mathrm{M})$ were performed in intact aortic rings previously incubated with or without $0.1 \mu \mathrm{M}$ T3 for 20 minutes. Endothelium-dependent and endothelium-independent relaxation were recorded for ACh and SNP, respectively, after maximal pre-contraction with $1 \mu \mathrm{M}$ PE.

Vascular Cells Culture

HAEC and human aortic VSMC were purchased from ATCC (Manassas, VA). HAEC were grown in Endothelial Growth Medium (EGM-2MV) from Lonza (Portsmounth, NH) and VSMC were grown in DMEM supplemented with $10 \%$ fetal bovine serum (FBS) and antibiotics and maintained at $37^{\circ} \mathrm{C}$ in a $5 \% \mathrm{CO}_{2}$ incubator. Prior to treatment with T3, cells were incubated in serum-free medium for 24 hours to reach a quiescent state [25]. After this period, cells were treated with $\mathrm{T} 3(0.1 \mu \mathrm{M})$ for a short period of 2 to 60 minutes. In some experiments, cells were pre-treated with $2 \mu \mathrm{M}$ of KT5823, a selective PKG inhibitor from Sigma Aldrich (St.Louis, MO, US), for 30 minutes. The concentration of KT5823 utilized in this study was chosen based on published reports $[26,27]$. To investigate whether T3 alters PKG mRNA and protein expression, quiescent human aortic VSMC were treated with T3 for 24 hours.

\section{Nitric Oxide Measurement}

4,5 Diaminofluorescein Diacetate Solution (DAF-FM) (cat. D23841, Life Technologies, Eugene, OR), an NO-sensitive fluorescence probe, was utilized to determine intracellular NO bioavailability in EC cultures. HAEC were loaded with $12.5 \mu \mathrm{M}$ of DAF-FM at $37^{\circ} \mathrm{C}$ for 45 minutes. The medium, containing loading dye, was discarded and replaced with fresh medium, and then incubated for an additional 30 minutes at $37^{\circ} \mathrm{C}$. Fluorescence was detected using an Olympus DP73 fluorescence microscope fitted with a camera. Relative fluorescence intensity was quantified using Image J software.

\section{Immunoblotting}

Protein expression was detected utilizing western blot. After treatment with T3, proteins were extracted from aortas and cells. $20 \mu \mathrm{g}-50 \mu \mathrm{g}$ of protein was separated by standard sodium dodecyl sulfate polyacrylamide gel electrophoresis (SDS-PAGE), transferred to polyvinylidene difluoride (PVDF) membranes, and immunoblotted with the following primary antibodies: total and phosphorylated eNOS (Cell Signaling Technology, Danvers, MA), total and phosphorylated VASP (Cell Signaling Technology, Danvers, MA), total and phosphorylated Akt (Cell Signaling Technology, Danvers, MA), PKG (Santa Cruz Biotechnology, Santa Cruz, CA) and their respective IgG-HRP secondary antibodies. Protein bands were detected using Lumigen ECL Ultra (Lumigen Inc., Southfield, MI). Membranes were stripped and re-probed with an internal loading control, $\beta$-actin (Cell Signaling Technology, Danvers, MA) or GAPDH (Cell Signaling Technology, Danvers, MA).

\section{Quantitative real time RT-PCR (RT-qPCR)}

Total RNA from human VSMC treated with T3 was extracted using Trizol. Total RNA concentrations were determined and RNA was converted into cDNA using the SuperScript III First-Strand Synthesis System (Thermo Scientific, Waltham, MA). RT-qPCR (Bio-Rad iQ SYBR Green) was performed to analyze relative gene expression of PKG. According to the standard protocol for SYBR Green, the following primers were utilized: PKG: 5-CCG AAT TCT GTA TTT CTC TTA CCT GCT TC-3 (forward), CAC ACT AGT GGA CTC AGT TTA ATT TGT GG (reverse) [28]. Primers utilized for SYBR Green, were synthetized by Integrated DNA Technologies. 
Statistical Analysis

All data are expressed as Mean \pm SEM. Results were analyzed using one-way or two-way analysis of variance (ANOVA, repeated measures when appropriate) followed by Bonferroni post hoc tests. Student $t$ test was used when appropriate. $\mathrm{P}<0.05$ was considered statistically significant.

\section{Results}

Rapid effect of T3 in vascular relaxation

To confirm that $\mathrm{T} 3$ rapidly augments vascular sensitivity to vasodilators agents, we performed vascular reactivity based on isometric tension studies. We found that rat aortic rings incubated with T3 for short term (20 minutes) had greater ACh-induced endotheliumdependent relaxation compared to control/vehicle group (Fig. 1A). Similar results were obtained using SNP, a nitric oxide donor. We observed that short term T3 incubation induced greater SNP-induced endothelium-independent relaxation compared to control/vehicle group (Fig. 1B). Aortic rings incubated with T3 in the presence of $2 \mu \mathrm{M}$ KT5823 displayed significant shift of the SNP curve to the right, demonstrating that inhibition of PKG abolishes the effect of T3 (Fig. 1D). The PKG inhibitor, when utilized by itself diminished responses to SNP only within high concentrations (Fig. 1C). Of note, pre-treatment of aortic rings with T3 $(0.1 \mu \mathrm{M})$ slightly decreased PE-induced precontraction; however, no significant change was detected.

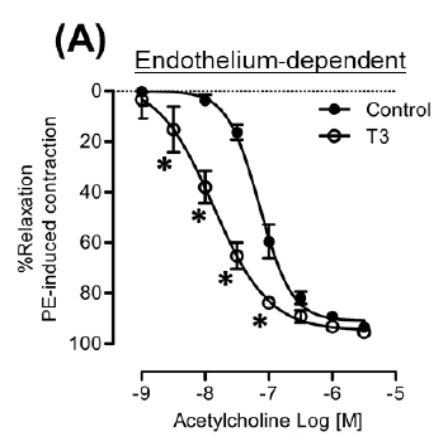

(C)

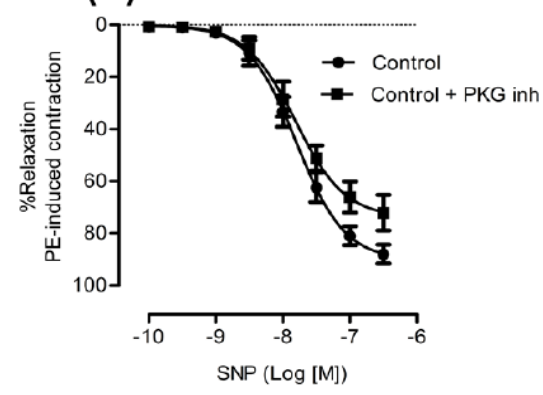

(B)

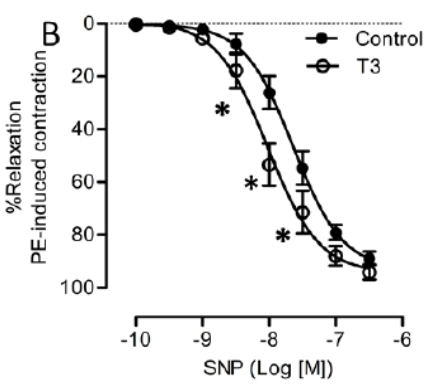

(D)

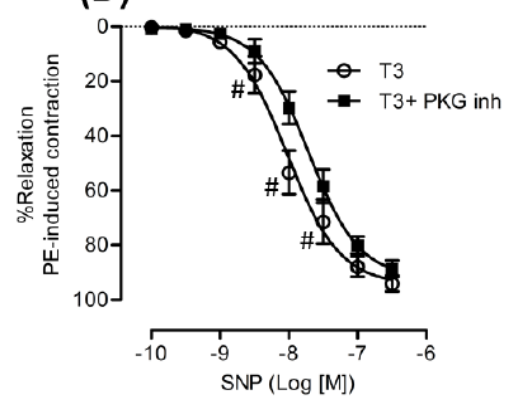

Fig. 1. T3 potentiates relaxation response in rat aortas via PKG pathway. Aortas were pre-incubated with $0.1 \mu \mathrm{M}$ T3 for 20 minutes. After this period, cumulative concentration curves for ACh (A) and SNP (B) were performed in aortas pre-contracted with phenylephrine (PE), to determine endothelium-dependent and independent relaxation, respectively. Curves for SNP in the absence and presence of $2 \mu \mathrm{M} \mathrm{KT5823,} \mathrm{a} \mathrm{PKG}$ inhibitor were performed in aortas from vehicle control group (C) and T3 incubation group (D). Vehicle control group (closed circles) and T3 incubation (open circles). All data are mean $\pm \mathrm{SEM}, \mathrm{n}=6,{ }^{*} \mathrm{p}<0.05$; \# $\mathrm{p}<0.05$ vs. T3. 
Fig. 2. T3 rapidly increases phosphorylation of Akt in human aortic endothelial cells (HAEC). Cells were treated with $0.1 \mu \mathrm{M}$ T3. Time (minutes) is indicated. After treatment, levels of phosphorylated Akt were assessed using western blot. (A) Representative immunoblots and (B) quantification of intensity of bands of four independent experiments are shown in the graph. All data are mean \pm SEM, $n=4,{ }^{*} p<0.005$ vs. control.

Fig. 3. T3 rapidly phosphorylates eNOS at Ser 1177 in HAEC. Cells were treated with $0.1 \mu \mathrm{M}$ T3. Time (minutes) is indicated. After treatment, levels of phosphorylated eNOS were assessed using western blot. (A) Representative immunoblots and (B) quantification of intensity of bands of four independent experiments are shown in the graph. All data are mean \pm SEM, $\mathrm{n}=4,{ }^{*} \mathrm{p}<0.001$ vs. control.

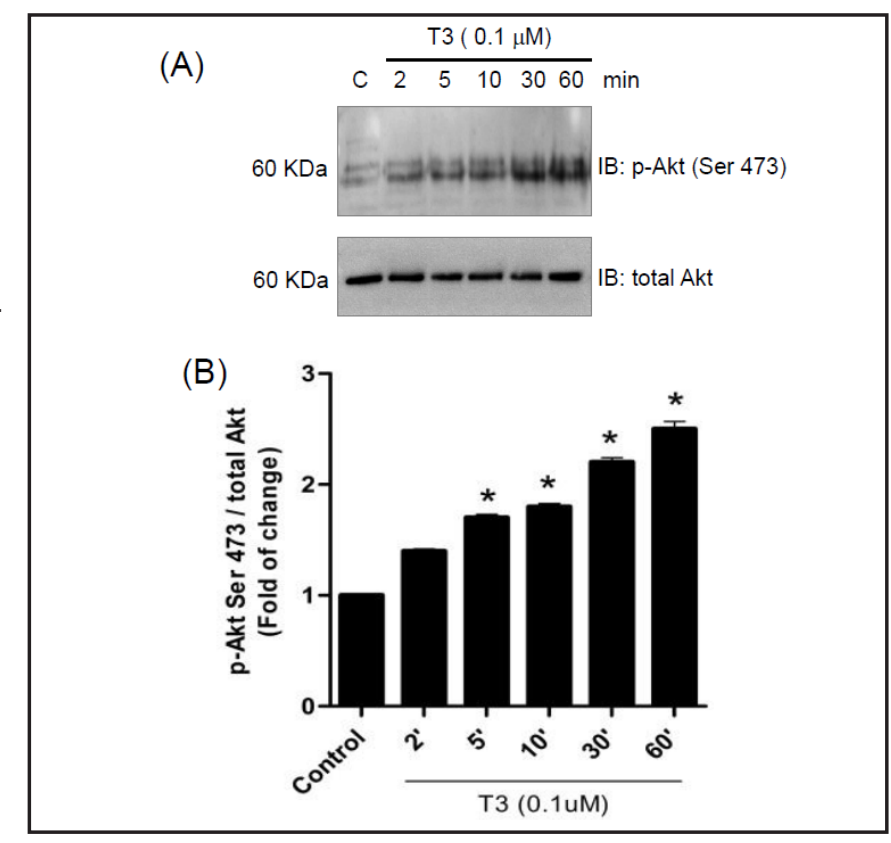

(A)

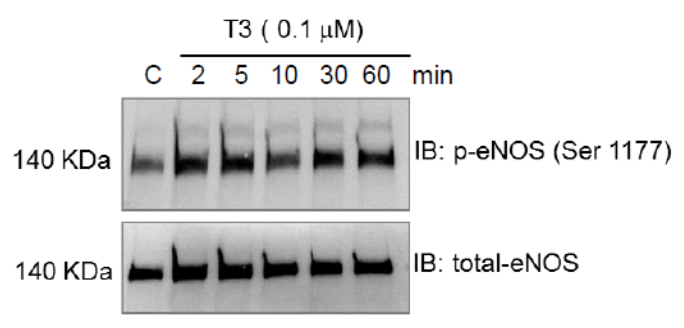

(B)

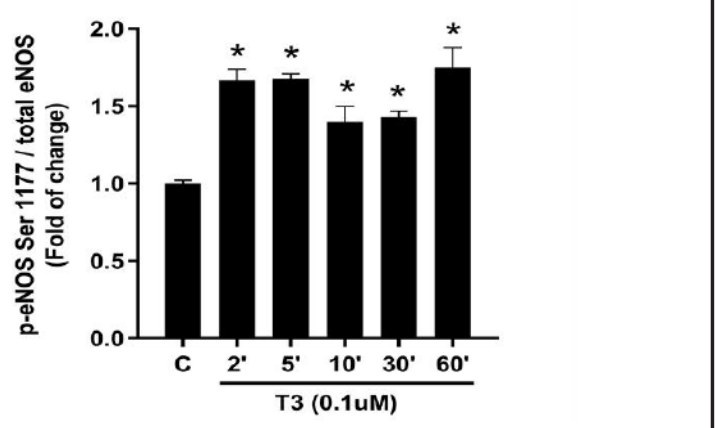

T3 activates the Akt/ eNOS pathway

It has been well established that Akt/eNOS activation is one of the main signaling pathways responsible for NO generation in EC [29]. To determine whether T3 activates this pathway, we stimulated HAEC with T3 for different periods of time. The concentration of T3 utilized was based on our previous studies [13]. We found that T3 rapidly increased phosphorylation of Akt and eNOS in a time-dependent manner. T3 was able to activate Akt within 5 minutes (Fig. 2), while eNOS was activated within 2 minutes (Fig. 3). In both situations, phosphorylation was sustained for 60 minutes.

\section{T3 induces NO production in EC}

NO is the major vascular relaxing factor released by EC [30]. Thus, we next examined whether T3 induces increased NO production in EC. HAEC were stimulated with T3 for 30 minutes. This time point was selected based on previous data showing that $\mathrm{T} 3$ activates both Akt and eNOS within 30 minutes. As shown in Fig. 4, T3 stimulated NO production in HAEC. 
Fig. 4. T3 rapidly increases levels of nitric oxide (NO) in endothelial cells. Endothelial cells were treated with $0.1 \mu \mathrm{M}$ T3 for 30 minutes. After treatment, NO production was detected utilizing DAF-FM probe. (A) Representative photomicrographs of the NO production (green fluorescent) and (B) quantification of four independent experiments are shown in the graph. All data are mean \pm SEM, $n=4,{ }^{*}$ p $<0.001$ vs. control.
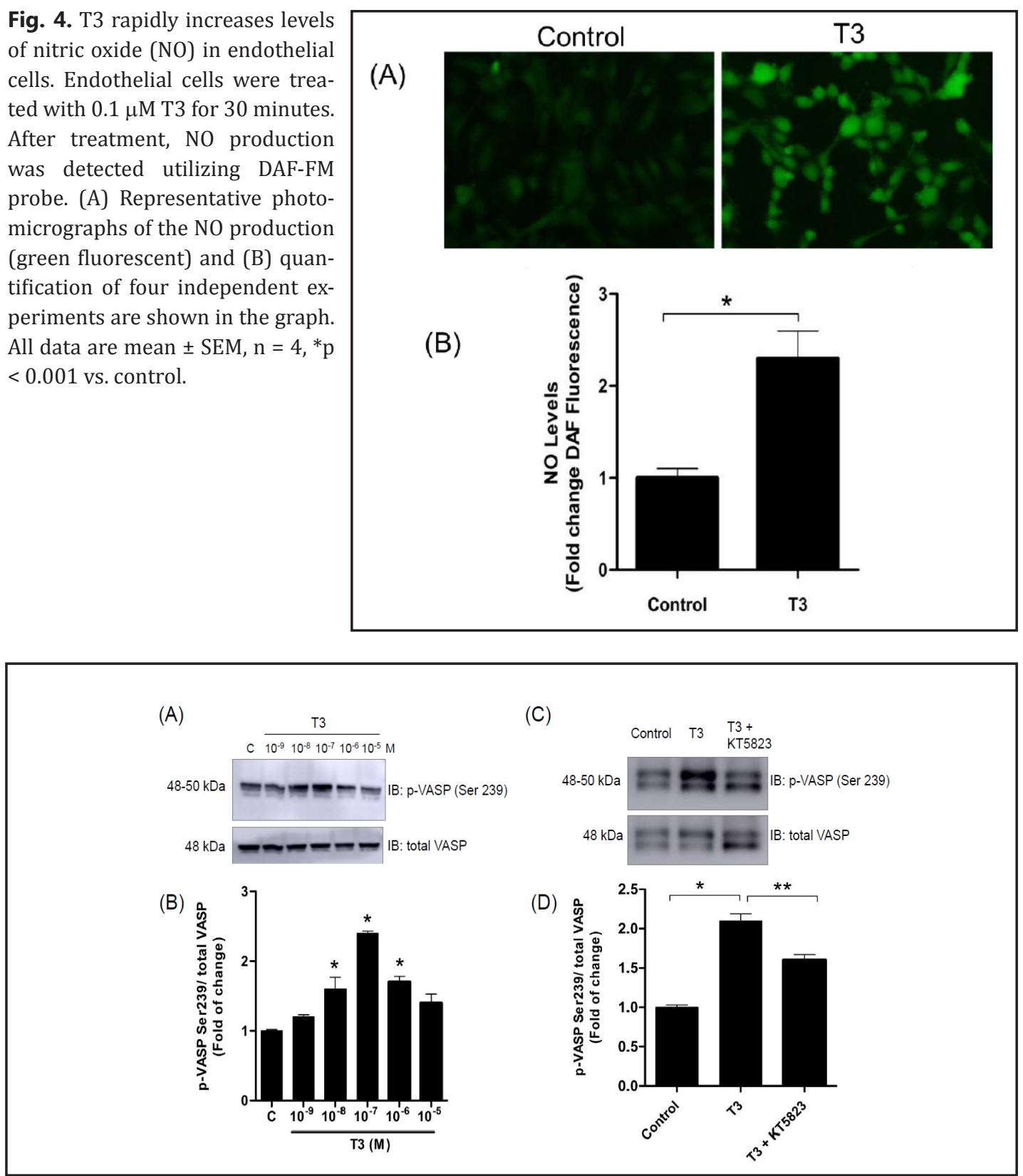

Fig. 5. T3 increases phosphorylation of VASP in VSMC. Concentration response curve for T3 $\left(10^{-9} \mathrm{M}\right.$ to $10^{-5}$ M) was performed in VSMC for 20 minutes and levels of phosphorylated VASP were assessed using western blot. (A) Representative immunoblots and (B) quantification of intensity of bands of four independent experiments is shown in the graph. In another set of experiments, VSMC were pre-treated with KT5823 $(2 \mu \mathrm{M})$, a PKG inhibitor, for 30 minutes followed by stimulation with $0.1 \mu \mathrm{M}$ T3 for 20 minutes. After treatment, levels of phosphorylated VASP were assessed using western blot. (C) Representative immunoblots and (D) quantification of bands of four independent experiments is shown in the graph. All data are mean \pm $\mathrm{SEM}, \mathrm{n}=4,{ }^{*} \mathrm{p}<0.05$ vs. control, ${ }^{* *} \mathrm{p}<0.01$ vs. T3 group.

T3 activates $P K G / V A S P$ signaling in aortic VSMC

We determined whether T3 alters PKG expression in aortic VSMC. Concentration-curve for T3 revealed that pharmacological concentrations of T3 induced phosphorylation of VASP (Fig. 5A and Fig.5B), a downstream target of PKG and a marker of relaxation [31]. This effect 


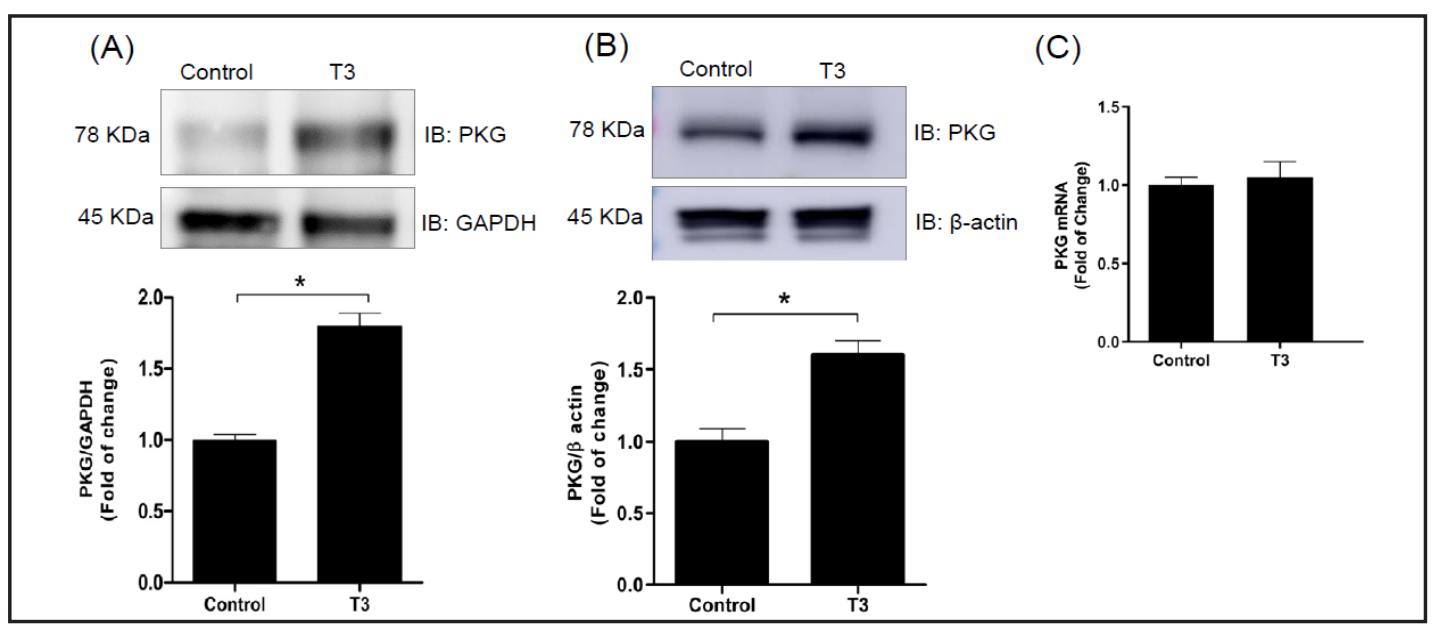

Fig. 6. T3 increases PKG expression in vasculature. (A) Isolated rat aortic rings and (B) human VSMC were treated with $0.1 \mu \mathrm{M}$ T3 for 24 hours. After treatment, levels of PKG were assessed using western blot. Top panels: representative immunoblots. Bottom panels: quantification of intensity of bands of four independent experiments. (C) mRNA levels of human VSMC treated with $0.1 \mu \mathrm{M}$ T3 for 24 hours were determined by RT-qPCR. All data are mean \pm SEM, $n=4,{ }^{*} p<0.05$ vs. control.

was reduced in the presence of a PKG inhibitor, as shown in Fig. 5C and Fig. 5D. Together, these results indicate that T3 activates the PKG/VASP signaling pathway, which in turn causes relaxation of VSMC. Moreover, we found that intact aortas from rat incubated with T3 for 24 hours displayed increased PKG expression (Fig. 6A). To confirm these results, we stimulated cultured human VSMC with T3 for the same period of time. As shown in Fig. 6B, T3 markedly increased PKG expression in VSMC, without altering PKG mRNA levels (Fig. 6C). Together, these results confirm that PKG is expressed in VSMC and that T3 alters PKG expression at protein levels. We further examined whether the PKG pathway is activated by T3.

\section{Discussion}

It is well-recognized that $\mathrm{T} 3$ mediates vascular relaxation via endothelium-dependent pathways. More recently, others and our group have demonstrated that T3 also potentiates vascular relaxation via endothelium-independent mechanisms, suggesting that VSMC are a new target for T3-mediated vasodilation $[10,13]$. The mechanisms underlying the rapid effects of T3 in mediating vascular relaxation remain poorly explored. The major findings of this study are that 1) T3 rapidly enhances vascular relaxation via an integrative non-genomic action comprising EC and VSMC, and 2) it involves PKG/VASP signaling activation in VSMC.

Clinical reports from Napoli et al. identified that T3 enhances endothelial function and exerts a direct and acute vasodilatory effect through an endothelium-dependent mechanism after T3 administration in the brachial artery [32]. Similarly, studies using isolated rat aortas have demonstrated that $\mathrm{T} 3$ induces endothelium-dependent vascular relaxation [20]. However, conflicting reports in the literature have demonstrated that $\mathrm{T} 3$ does not causes vasorelaxation per se, and that only high concentrations of T3 are able to causes relaxation in small vessels such as mesenteric and femoral arteries [10]. In this present study, we found that aortas acutely stimulated with $\mathrm{T} 3$ do not cause relaxation by itself but markedly potentiated vascular relaxation in response to vasoactive agents ACh and SNP. These results showed that T3 plays an important role in sensitizing arteries to vasodilatory agents.

Mechanistically, it has been demonstrated that T3 causes vascular relaxation through phosphorylation of Akt, leading to phosphorylation of eNOS at serine 1177 and NO production in EC [20]. Likewise, we found that T3 leads to NO production in human aortic EC via phosphorylation of Akt and consequently activation of eNOS in a time-dependent manner. 
Fig. 7. Schematic summary of the present study. T3 activates a PKG/VASP pathway in VSMC, resulting in vascular relaxation. T3 increases NO release via PI3K/Akt signaling pathway in EC (solid arrow). T3 directly increases NO production in VSMC (dashed arrow) via nNOS and iNOS. NO diffuses into VSMC, leading to the activation of cyclic guanosine monophosphate (cGMP)-dependent protein kinase G (PKG) signaling pathway. PKG phosphorylates VASP at Ser 239 and causes vascular relaxation.

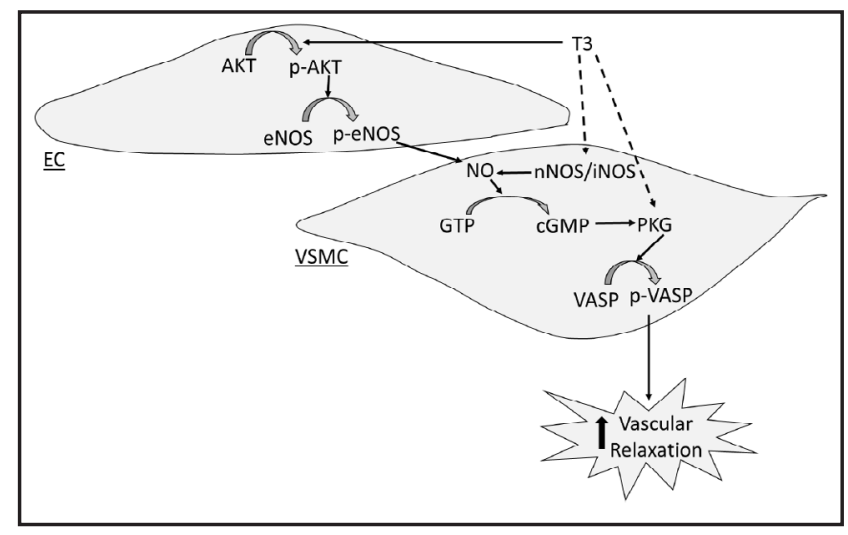

NO produced in EC diffuse to VSMC and further activate signaling pathways implicated in vasodilatory effects. We have previously showed that $\mathrm{T} 3$ reduces vascular contraction via its direct effect on VSMC [13]. In the present study, we aimed to determine whether T3 also affects the vascular relaxation response through a direct effect of T3 on VSMC. We found in our functional vascular study using wire myograph and SNP as a vasodilator which acts directly on VSMC, that T3 acutely displays an increase in endothelium-independent relaxation, indicating that T3 mediates relaxation via VSMC. These findings imply that T3 also has a nongenomic effect on VSMC. For years, studies have suggested that T3 causes vascular relaxation exclusively via EC. However, compelling data support a rapid vasorelaxant effect of T3 also occurring via VSMC $[11,33]$. Therefore, identification of vasodilatory mechanisms activated independently of endothelium by T3 is imperative.

PKG signaling pathways have recently been reported to mediate vascular smooth muscle relaxation $[34,35]$. One of the mechanisms by which PKG causes vasodilation involves activation of ion channels. Once activated, PKG stimulates potassium ion channels in the VSMC plasma membrane, which increases potassium efflux and consequently membrane hyperpolarization [36]. Additionally, PKG reduces the concentration of intracellular calcium ions, resulting in vascular relaxation [37-40]. Furthermore, it has been proposed that activation of PKG signaling augments vasorelaxation via dephosphorylation of myosin light chain (MLC). Of note, phosphorylated MLC is one of the major markers of vascular contraction [41].

NO has been considered the major stimulator of PKG [19]. Recent findings have suggested that activation of PKG in VSMC leads to phosphorylation of VASP at serine 239, a specific target of PKG signaling and marker of vasodilation [42]. In our study, we found that inhibition of PKG abolished T3 mediated relaxation in isolated aortas. Intriguingly, we did not observe the effect of PKG inhibitor in the SNP curve performed in aortas from control rats. This is not consistent with a previous study that has demonstrated that relaxation induced by SNP is decreased by PKG inhibitor [43]. The reason underlying this discrepancy may be due to the different methods utilized. While we used rat aortas, the previous report used smooth muscle strip from rabbit stomach [43].

Using cultured human VSMC, we found that pharmacological concentration of T3 rapidly phosphorylates VASP at serine 239 and this effect was blunted in the presence of a PKG inhibitor. In addition, we found that long-term (24 hours) stimulation with T3 did not alter mRNA levels of PKG but increased PKG protein expression in VSMC, suggesting that impairment of proteolytic mechanisms, such as ubiquitin proteasome-mediated protein degradation may be involved in T3-induced increased PKG protein expression [44].

Together, these findings strongly indicate that the PKG/VASP signaling pathway is involved in the endothelium-independent vasodilatory effects of T3 (Fig. 7). Most importantly, our findings reveal new therapeutic possibilities using T3 as a vasodilatory agent, mainly in treating vascular disorders in which the endothelium is dysfunctional. 
In conclusion, our results suggest that $\mathrm{T} 3$ has a vasoprotective effect, endorsing it as a potential therapeutic approach to treat vascular disease that involves impaired vasodilation. To further confirm the clinical relevance of utilizing T3 as a safe vasoprotective agent, future studies are warranted to test the safety and efficiency of T3 in models of cardiovascular disease.

\section{Acknowledgements}

This work was supported by Faculty Development Grant from NYITCOM (MACS) and the National Heart, Lung, and Blood Institute of the National Institutes of Health, Bethesda MD, under award R01HL103671 (AMG). The content is solely the responsibility of the authors and does not necessarily represent the official views of the National Institute of Heath. Additional support was provided by the National Natural Science Foundation of China N. 81470485 (YDT).

\section{Disclosure Statement}

The authors have no conflict of interest for this study.

\section{References}

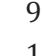

Klein I, Ojamaa K: Thyroid hormone and the cardiovascular system. N Engl J Med 2001;344:501-509. Klein I, Danzi S: Thyroid disease and the heart. Circulation 2007;116:1725-1735.

Jabbar A, Pingitore A, Pearce SH, Zaman A, Iervasi G, Razvi S: Thyroid hormones and cardiovascular disease. Nat Rev Cardiol 2017;14:39-55.

Bianco AC, Salvatore D, Gereben B, Berry MJ, Larsen PR: Biochemistry, cellular and molecular biology, and physiological roles of the iodothyronine selenodeiodinases. Endocr Rev 2002;23:38-89.

Sabatino L, Lubrano V, Balzan S, Kusmic C, Del Turco S, Iervasi G: Thyroid hormone deiodinases D1, D2, and D3 are expressed in human endothelial dermal microvascular line: effects of thyroid hormones. Mol Cell Biochem 2015;399:87-94.

Pol CJ, Muller A, Zuidwijk MJ, van Deel ED, Kaptein E, Saba A, Marchini M, Zucchi R, Visser TJ, Paulus WJ, Duncker DJ, Simonides WS: Left-ventricular remodeling after myocardial infarction is associated with a cardiomyocyte-specific hypothyroid condition. Endocrinology 2011;152:669-679.

Weltman NY, Pol CJ, Zhang Y, Wang Y, Koder A, Raza S, Zucchi R, Saba A, Colligiani D, Gerdes AM: Long-term physiological T3 supplementation in hypertensive heart disease in rats. Am J Physiol Heart Circ Physiol 2015;309:H1059-1065.

Weltman NY, Ojamaa K, Schlenker EH, Chen YF, Zucchi R, Saba A, Colligiani D, Rajagopalan V, Pol CJ, Gerdes AM: Low-dose T(3) replacement restores depressed cardiac T(3) levels, preserves coronary microvasculature and attenuates cardiac dysfunction in experimental diabetes mellitus. Mol Med 2014;20:302-312.

Gerdes AM, Ojamaa K: Thyroid Hormone and Cardioprotection. Compr Physiol 2016;6:1199-1219. Cai Y, Manio MM, Leung GP, Xu A, Tang EH, Vanhoutte PM: Thyroid hormone affects both endothelial and vascular smooth muscle cells in rat arteries. Eur J Pharmacol 2015;747:18-28.

Ojamaa K, Klemperer JD, Klein I: Acute effects of thyroid hormone on vascular smooth muscle. Thyroid 1996;6:505-512.

2 Yoneda K, Takasu N, Higa S, Oshiro C, Oshiro Y, Shimabukuro M, Asahi T: Direct effects of thyroid hormones on rat coronary artery: nongenomic effects of triiodothyronine and thyroxine. Thyroid 1998;8:609-613.

Carrillo-Sepulveda MA, Ceravolo GS, Fortes ZB, Carvalho MH, Tostes RC, Laurindo FR, Webb RC, BarretoChaves ML: Thyroid hormone stimulates NO production via activation of the PI3K/Akt pathway in vascular myocytes. Cardiovasc Res 2010;85:560-570. 


\section{Cellular Physiology Cell Physiol Biochem 2017;41:1894-1904

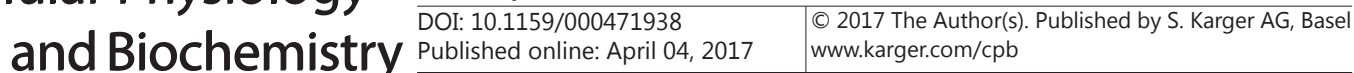

Samuel et al.: Vasodilatory Effect of T3 and PKG/VASP Signaling Pathway

14 van Mullem AA, van Gucht AL, Visser WE, Meima ME, Peeters RP, Visser TJ: Effects of thyroid hormone transporters MCT8 and MCT10 on nuclear activity of T3. Mol Cell Endocrinol 2016;437:252-260.

15 Cheng SY, Leonard JL, Davis PJ: Molecular aspects of thyroid hormone actions. Endocr Rev 2010;31:139170.

16 Chettimada S, Rawat DK, Dey N, Kobelja R, Simms Z, Wolin MS, Lincoln TM, Gupte SA: Glc-6-PD and PKG contribute to hypoxia-induced decrease in smooth muscle cell contractile phenotype proteins in pulmonary artery. Am J Physiol Lung Cell Mol Physiol 2012;303:L64-74.

17 Davis PJ, Davis FB, Mousa SA, Luidens MK, Lin HY: Membrane receptor for thyroid hormone: physiologic and pharmacologic implications. Annu Rev Pharmacol Toxicol 2011;51:99-115.

18 Neo BH, Kandhi S, Wolin MS: Roles for soluble guanylate cyclase and a thiol oxidation-elicited subunit dimerization of protein kinase G in pulmonary artery relaxation to hydrogen peroxide. Am J Physiol Heart Circ Physiol 2010;299:H1235-1241.

19 Sausbier M, Schubert R, Voigt V, Hirneiss C, Pfeifer A, Korth M, Kleppisch T, Ruth P, Hofmann F: Mechanisms of NO/cGMP-dependent vasorelaxation. Circ Res 2000;87:825-830.

-20 Hiroi Y, Kim HH, Ying H, Furuya F, Huang Z, Simoncini T, Noma K, Ueki K, Nguyen NH, Scanlan TS, Moskowitz MA, Cheng SY, Liao JK: Rapid nongenomic actions of thyroid hormone. Proc Natl Acad Sci USA 2006;103:14104-14109.

21 Davel AP, Victorio JA, Delbin MA, Fukuda LE, Rossoni LV: Enhanced endothelium-dependent relaxation of rat pulmonary artery following beta-adrenergic overstimulation: involvement of the NO/cGMP/VASP pathway. Life Sci 2015;125:49-56.

-22 Schafer A, Burkhardt M, Vollkommer T, Bauersachs J, Munzel T, Walter U, Smolenski A: Endotheliumdependent and -independent relaxation and VASP serines 157/239 phosphorylation by cyclic nucleotideelevating vasodilators in rat aorta. Biochem Pharmacol 2003;65:397-405.

23 Pfeifer A, Klatt P, Massberg S, Ny L, Sausbier M, Hirneiss C, Wang GX, Korth M, Aszodi A, Andersson KE, Krombach F, Mayerhofer A, Ruth P, Fassler R, Hofmann F: Defective smooth muscle regulation in cGMP kinase I-deficient mice. EMBO J 1998;17:3045-3051.

-24 Zhong X, Wang Y, Wu J, Sun A, Yang F, Zheng D, Li T, Dong S, Zhao Y, Yang G, Xu C, Sun D, Lu F, Zhang W: Calcium sensing receptor regulating smooth muscle cells proliferation through initiating cystathioninegamma-lyase/hydrogen sulfide pathway in diabetic rat. Cell Physiol Biochem 2015;35:1582-1598.

25 Huang K, Yan ZQ, Zhao D, Chen SG, Gao LZ, Zhang P, Shen BR, Han HC, Qi YX, Jiang ZL: SIRT1 and FOXO Mediate Contractile Differentiation of Vascular Smooth Muscle Cells under Cyclic Stretch. Cell Physiol Biochem 2015;37:1817-1829.

26 Ranek MJ, Terpstra EJ, Li J, Kass DA, Wang X: Protein kinase g positively regulates proteasome-mediated degradation of misfolded proteins. Circulation 2013;128:365-376.

27 Hesabi B, Danziger RS, Kotlo KU: Heterogeneous nuclear ribonucleoprotein A1 is a novel cellular target of atrial natriuretic peptide signaling in renal epithelial cells. Cell Signal 2012;24:1100-1108.

28 Zeng Y, Pan Y, Liu H, Kang K, Wu Y, Hui G, Peng W, Ramchandran R, Raj JU, Gou D: MiR-20a regulates the PRKG1 gene by targeting its coding region in pulmonary arterial smooth muscle cells. FEBS Lett 2014;588:4677-4685.

29 Fulton D, Gratton JP, McCabe TJ, Fontana J, Fujio Y, Walsh K, Franke TF, Papapetropoulos A, Sessa WC: Regulation of endothelium-derived nitric oxide production by the protein kinase Akt. Nature 1999;399:597-601.

-30 Palmer RM, Ashton DS, Moncada S: Vascular endothelial cells synthesize nitric oxide from L-arginine. Nature 1988;333:664-666.

-31 Ibarra-Alvarado C, Galle J, Melichar VO, Mameghani A, Schmidt HH: Phosphorylation of blood vessel vasodilator-stimulated phosphoprotein at serine 239 as a functional biochemical marker of endothelial nitric oxide/cyclic GMP signaling. Mol Pharmacol 2002;61:312-319.

32 Napoli R, Guardasole V, Angelini V, Zarra E, Terracciano D, D'Anna C, Matarazzo M, Oliviero U, Macchia V, Sacca L: Acute effects of triiodothyronine on endothelial function in human subjects. J Clin Endocrinol Metab 2007;92:250-254.

33 Park KW, Dai HB, Ojamaa K, Lowenstein E, Klein I, Sellke FW: The direct vasomotor effect of thyroid hormones on rat skeletal muscle resistance arteries. Anesth Analg 1997;85:734-738.

-34 Lin CS, Liu X, Tu R, Chow S, Lue TF: Age-related decrease of protein kinase G activation in vascular smooth muscle cells. Biochem Biophys Res Commun 2001;287:244-248. 


\section{Cellular Physiology Cell Physiol Biochem 2017;41:1894-1904

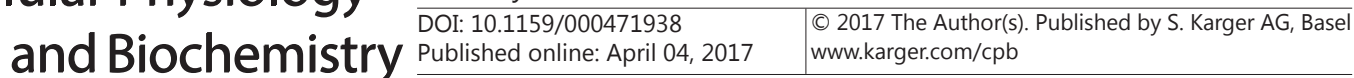

Samuel et al.: Vasodilatory Effect of T3 and PKG/VASP Signaling Pathway

35 Li L, Hu M, Zheng L, Zhang C, Li J, Rong R, Zhu T, Jia Y: Endothelin Receptor Down-Regulation Mediated Ligand Regulation Mechanisms Protect Against Cellular Hypoxia Injury in Rat Vascular Endothelial Cells. Cell Physiol Biochem 2016;40:1443-1454.

-36 Monteiro FS, Silva AC, Martins IR, Correia AC, Basilio IJ, Agra MF, Bhattacharyya J, Silva BA: Vasorelaxant action of the total alkaloid fraction obtained from Solanum paludosum Moric. (Solanaceae) involves NO/ cGMP/PKG pathway and potassium channels. J Ethnopharmacol 2012;141:895-900.

-37 Yao X, Kwan HY, Chan FL, Chan NW, Huang Y: A protein kinase G-sensitive channel mediates flow-induced $\mathrm{Ca}(2+)$ entry into vascular endothelial cells. FASEB J 2000;14:932-938.

-38 Edwards A, Cao C, Pallone TL: Cellular mechanisms underlying nitric oxide-induced vasodilation of descending vasa recta. Am J Physiol Renal Physiol 2011;300:F441-456.

39 Fellner SK, Arendshorst WJ: Complex interactions of NO/cGMP/PKG systems on Ca2+ signaling in afferent arteriolar vascular smooth muscle. Am J Physiol Heart Circ Physiol 2010;298:H144-151.

-40 Moncada S, Higgs EA: The discovery of nitric oxide and its role in vascular biology. Br J Pharmacol 2006;147:S193-201.

41 Lincoln TM: Myosin phosphatase regulatory pathways: different functions or redundant functions? Circ Res 2007;100:10-12.

42 Holt AW, Martin DN, Shaver PR, Adderley SP, Stone JD, Joshi CN, Francisco JT, Lust RM, Weidner DA, Shewchuk BM, Tulis DA: Soluble guanylyl cyclase-activated cyclic GMP-dependent protein kinase inhibits arterial smooth muscle cell migration independent of VASP-serine 239 phosphorylation. Cell Signal 2016;28:1364-1379.

-43 Murthy KS: cAMP inhibits IP(3)-dependent $\mathrm{Ca}(2+)$ release by preferential activation of cGMP-primed PKG. Am J Physiol Gastrointest Liver Physiol 2001;281:G1238-1245.

44 Bonifacino JS, Weissman AM: Ubiquitin and the control of protein fate in the secretory and endocytic pathways. Annu Rev Cell Dev Biol 1998;14:19-57. 